\title{
Yenidoğan Döneminde Hipoglisemiye Yaklaşım
}

\author{
Management of Hypoglycemia in Neonatal Period
}

\section{Özlem Sangün, Bumin Dündar \\ Süleyman Demirel Üniversitesi Tıp Fakültesi, Çocuk Sağı̆ğı ve Hastalıkları Anabilim Dall, Çocuk Endokrinoloji Bilim Dall, Isparta, Türkiye}

Yazışma Adresi/Address for Correspondence Dr. Bumin Dündar, Katip Çelebi Üniversitesi Tip Fakültesi, Çocuk Sağığı ve Hastalkkları Anabilim Dall, Çocuk Endokrinoloji Bilim Dall, lzmir, Türkiye Tel.: +902324696969 E-posta: bumindundar@gmail.com

Geliş Tarihi/Received: 11.04.2012 Kabul Tarihi/Accepted: 26.07.2012

(c) Güncel Pediatri Dergisi, Galenos Yayınevi tarafindan basılmış̧ır.

(c) The Journal of Current Pediatrics, published by Galenos Publishing.

\begin{abstract}
ÖZET
Yenidoğanların enerji gereksinimi fazla, birçok enzim sistemleri ve substratları ise sıklıkla yetersizdir. Bu yüzden yenidoğan döneminde hipoglisemiye yatkınlık fazladır. Bu dönemde gözlenen hipoglisemiler, sıklıkla geçici karakterde olup, spesifik klinik bulgu vermezler. Yenidoğanın keton ve laktat gibi alternatif enerji kaynakları düşüktür ve glukoz yenidoğanın başlıca enerji kaynağı olup, temel olarak beyin tarafından kullanılır. Günümüzde hipogliseminin nörogelişimsel gerilik ve kalıcı nörolojik hasarla ilişkili olduğu bilinmekte ve riskli bebeklerin korunması için hipoglisemi sınırları, izlem gerektiren durumlar ve tedavi protokolleri konusunda yaklaşımlar geliştirilmeye çalışılmaktadır. Hipoglisemi tedavisi özellikle de hasta semptomatikse acildir ve nedene yönelik araştırmalar devam ederken başlatımalıdır. Postnatal erken dönemde ve özellikle anne sütü ile beslenme yenidoğanı hipoglisemiden korumakta oldukça etkilidir. Dirençli ve uzun süren hipoglisemilerde ileri araştırmalar yapılmalı ve nedene yönelik tedaviler uygulanmalıdır. (Güncel Pediatri 2013; 11: 31-8)
\end{abstract}

Anahtar kelimeler: Yenidoğan, hipoglisemi, tedavi

\section{SUMMARY}

Although neonates have high energy requirement, most of their enzyme systems are immature and substrates are inadequate. Therefore they have a predisposition for hypoglycemia. There are no specific clinic symptoms and signs for hypoglycemia in neonatal period and it is usually transient. Alternative energy sources of the neonate like ketones and lactate are low and glucose is the major source of energy which is mainly used by the brain. Due to well known relation of hypoglycemia with neurodevelopemental delay and neurologic impairment, levels of hypoglycemia for at risk babies, conditions which require monitoring and treatment protocols are studied on. Treatment of hypoglycemia is an emergency especially when the patient is symptomatic and must be initiated together with the etiologic investigation. Early postnatal feeding particularly with human milk is quite effective in preventing from neonatal hypoglycemia. Further investigation must be performed in prolonged or resistant hypoglycemia which requires etiology-oriented approach. (Journal of Current Pediatrics 2013; 11: 31-8)

Key words: Neonatal, hypoglycemia, management

\section{Giriş}

Hipoglisemi, yenidoğanın en sık görülen metabolik sorunudur. Yenidoğanların enerji gereksinimi, büyük çocuklara göre 2-3 kat daha fazla iken enerji üretiminde yer alan enzim sistemlerinin ve substratların yetersiz olması dolayısıyla, bu dönemde hipoglisemiye yatkınlık fazladır (1-4). Hipoglisemi sıklığı yaklaşık 1000 canlı doğumda 5 olarak bildirilmekte, çok düşük doğum ağırlıklı bebeklerde bu oran \%15 seviyelerine çıkmaktadır (5).

Çocukluk çağı hipoglisemileri uzun zamandır bilinmesine karşın yenidoğan ve süt çocuklarında hipoglisemi, son 70 yılda tanımlanabilmiş, sıklıkla geçici karakterde olması ve spesifik bir klinik bulgu vermemesi sebebiyle önceleri zararsız ve fizyolojik bir durum olarak kabul edilmiş̦tir. Ayrıca; apne, siyanoz, koma ve konvülsiyona varan bulgularla birlikteliği yaklaşık 20 yıl sonra ortaya konabilmiştir $(6,7)$. Hipoglisemiye yol açabilecek risk faktörleri, hipoglisemi sınırları, kan glukoz seviyesi ile santral sinir sistemi hasarı arasındaki ilişkiler, tedavi edilmesi gereken kritik değerler ve hipogliseminin uzun dönem sonuçları konularında konsensüs elde etmek ise halen mümkün olamamıştır.

\section{Glukoz Homeostazı}

\section{Fetüste Glukoz Homeostazı}

Fetusun intrauterin dönemde glukoz intiyacı anneden karşılanır $(8,9)$. Plasentadaki major glukoz taşıyıcı izoformu 
GLUT1'dir ve insülinden bağımsızdır (10). Ortalama fetal glukoz tüketimi, yaklaşık $5 \mathrm{mg} / \mathrm{kg} / \mathrm{dk}$ olup, doğum sonrası endojen glukoz üretim hızına yakın bir değerdedir. Glukoz, kolaylaştırılmış difüzyonla plasentadan geçer ve genellikle fetal plazma glukoz konsantrasyonu, annenin venöz plazma glukozunun \%70-80'i kadardır. Glukoneogenez ve glukojenolizde yer alan enzim sistemleri fetal karaciğerde mevcut olmasına karşın annede şiddetli açlık gelişmedikçe inaktif durumdadırlar (1). Bu durumun, fetal cAMP sisteminin immatür olmasıyla ilișkili olduğu düșünülmekte ve fetüsün akut hipoglisemi ve hiperglisemiye hemen yanıt veremediği bilinmektedir (10). Karaciğer glikojen depolarının ve yağ dokusunun artması, gestasyonun son aylarında gerçekleşmektedir (11).

\section{Doğumla Birlikte Glukoz Homeostazında Oluşan \\ Değişiklikler}

Doğumda anneden geçen glukozun birden kesilmesiyle birlikte, glukagon konsantrasyonunda dakikalar içinde 3-5 katına varan bir artış gerçekleşir. Kan glukoz düzeyi 1-2. saatte en düşük değerine ulaşır daha sonra yükselerek 2-4 saatte plato değerini oluşturur. Insülin seviyesi düşer ve birkaç gün boyunca düşük kalır. Doğum stresiyle artan epinefrin, glukagon ve büyüme hormonu $(\mathrm{BH})$ 'nu artııırken, insülin düzeylerini baskılar. Ayrıca doğumdan sonra insülin reseptörleri sayıca azalırken, glukagon reseptörleri aktive olur. Bu sistemlerin uyumlu bir şekilde çalışmasıyla artan glukoz, serbest yağ asidi ve keton cisimleri yakıt olarak kullanılır. Bu dönemde yenidoğan beyni ketonları, glukozdan daha aktif olarak kullanabilir. Glikojen depoları kullanıldıktan sonra glukoneogenez yolu aktiflenerek, kan glukoz düzeyleri sabit tutulmaya çalışılır $(1,10,11,12)$. Preterm bebeklerde, glikojen ve yağ depolarının yetersiz olmasının yanı sıra, glukoneogenez ve ketogenez yolaklarının göreceli immatüritesi sıklıkla daha düşük kan glukoz seviyelerinin saptanmasına yol açar. Bu durum sıklıkla fizyolojik olarak adlandırılsa da, pretermlerin hipogliseminin olumsuz etkilerine daha dayanıklı olduğunu gösteren kanıt yoktur $(1,13)$.

\section{Hipogliseminin Olumsuz Etkileri}

Bugün, hipogliseminin hücreleri glukozdan yoksun bırakarak değil, aktif eksitotoksik etkisiyle öldürdüğü bilinmektedir. Tekrarlayan hipoglisemiler nöron harabiyeti, aspartat ve benzeri eksitatuar aminoasitlerin artışı ve dendrit kaybı yaratarak, nöromotor gelişme geriliği, fokal nörolojik defisitler, hareket bozuklukları, konuşma bozuklukları mikrosefali ve santral pontin miyelinoza yol açabilir $(10,14,15,16)$. Nörolojik morbidite özellikle şiddetli, dirençli ve semptomatik hipoglisemilere eşlik etmekte, sağlıklı term bebeklerde görülen geçici hipoglisemilerin belirgin nörogelişimsel hasara yol açmadığı bilinmektedir $(17,18)$. Ancak çok şiddetli olmasa de tekrarlayan orta düzeyde hipoglisemilerin davranış bozukluklarına yol açtığı hayvan deneyleriyle gösterilmiştir (19).

Birçok metabolik hastalığın aksine, hipogliseminin beyinde yarattığı hasar asimetriktir ve hemisferler arasındaki elektroserebral sessizliğin eş zamanlı başlamamasının bu asimetrinin sebebi olduğu ifade edilmiştir (Hipoglisemi, izoelektrik EEG varlığında nöron harabiyeti yapmaktadır). Dentat girus, karakteristik olarak etkilenir $(1,16)$.

\section{Tanım}

Literatürde hipoglisemi sınırları konusunda tam bir görüş birliği yoktur. Koh ve ark. (20) 178 pediatrist ile yaptıkları bir anket çalışmasında term yenidoğanlarda 18-70 mg/dl arasında, bu konuda yazıımış temel kitapları incelediklerinde ise 18-45 $\mathrm{mg} / \mathrm{dl}$ arasında değişen hipoglisemi tanımlamalarının bulunduğunu görmüşlerdir. Asemptomatik term bebeklerde plazma glukoz konsantrasyonu persistan olarak $36 \mathrm{mg} / \mathrm{dl}$ altında olmadıkça ya da kısa süreli de olsa 20-25 mg/ dl altına inmedikçe müdahale edilmesini gereksiz bulan görüşlerin yanı sıra, her yaş grubunda $50 \mathrm{mg} / \mathrm{dl}$ 'nin altını hipoglisemi kabul etmek gerektiğini savunan görüşler de vardır $(10,21,22)$. Birçok yazar kan/plazma glukozunun postnatal ilk birkaç saatin ardından $>45 \mathrm{mg} / \mathrm{dl}$ olmasını önermiştir, ancak bu değerlerin altında her zaman kalıcı hipoglisemik beyin hasarı olduğunu söyleyebilmek mümkün değildir (12,23-25). Bebeğin doğum haftası, doğum ağırlığı, beslenme durumu, ek hastalıkları, vücut depoları ve alternatif enerji kaynakları gibi faktörler "normal" kan glukoz değerini değiştirebilirler. Örneğin hipoksi ve hiperinsülinizmde glukoz düzeyi hedeflerinin daha yüksek tutulması gerektiği önerilmektedir.

Son yıllarda, hipoglisemi ile ilgili olarak, "müdahale sınıı” kavramı üzerinde durulmaktadır (26). Müdahale sınırı,"klinisyenin güncel literatür ışığında, müdahale edilmesi gerektiğini düşündüğü tam kan ya da plazma glukoz konsantrasyonu" olarak tanımlanmaktadır ve uygun kanıtlar elde edilinceye kadar, bu değerin kan glukozu için $40 \mathrm{mg} / \mathrm{dl}$, plazma glukozu için $45 \mathrm{mg} / \mathrm{dl}$ olduğuna inanılmaktadır $(27,28)$. En kolay tanının, düşük kan glukoz düzeyleri saptandığında ortaya çıkan klinik semptomların, öglisemi sağlandığında kaybolması ile konabileceği de ifade edilmiştir ve semptomların ortaya çıktığı değer, bu seviyelerin üstünde bile olsa tedavi edilebilir (21).

\section{İzlem Gerektiren Yüksek Riskli Durumlar}

Zamanında doğmuş, sağılılı görünümde, yaşına göre normal ağırlıkta olan (AGA) ve anne sütü ile beslenen 
yenidoğanlarda kan şekeri izlemi önerilmemektedir. Anne sütü alan bebeklerin daha düşük kan glukoz seviyelerine rağmen, beyin için alternatif bir yakıt olan keton seviyelerinin yüksek bulunduğu bildirilmiştir (29). Hipoglisemi açısından yüksek riskli kabul edilen durumlar Tablo 1'de belirtilmiştir. Bu bebeklerde postnatal 2. saatten başlayarak, riskleri azalana değin 3-6 saat aralarla kan şekeri izlemi önerilmektedir. Intravenöz sıvı alan bebeklerde oral beslenmeye geçildikten sonra üst üste $2 \mathrm{kez} 50 \mathrm{mg} /$ dl'nin üzerinde değer görülmeli ve en az 48 saat daha izlem devam ettirilmelidir $(31,32)$.

\section{Semptomlar}

Yenidoğanlarda hipoglisemi semptomları sıklıkla nonspesifik olup, birçok hastalığı taklit edebilir. Bu yüzden sepsis gibi ağır sistemik hastalıklar dışlanmalıdır. Sık görülen belirti ve bulgular Tablo 2'de özetlenmiştir.

\section{Glukoz Ölçüm Yöntemleri}

Hasta başı glukoz ölçüm çubuklarl: Çok düşük miktarda (0,3 $\mu$ l'ye varan) kanla hızlı ölçüm yapabilme özelliklerine rağmen güvenilirlikleri azdır. Yenidoğan plazmasında sıklıkla yüksek saptanan hemoglobin, bilirubin ve trigliserid düzeylerinin ölçüm doğruluğunu etkilediği gösterilmiş̧ir Glukoz oksidaz ya da glukoz dehidrogenaz enzim reaksiyonu üzerinden ölçüm yaparlar. Özellikle 40-50 mg/ dl gibi düşük değerlerde mutlaka venöz kanla ve diğer laboratuvar yöntemleriyle doğrulanmalı, ancak bu arada eldeki glukoz değerine göre tedavi edilmesi gerekiyorsa gecikilmemelidir $(31,34)$.

Sürekli cilt altı glukoz izleme sistemleri: Özellikle yoğun bakım koşullarında, sürekli oksijen satürasyonu izlemi gibi kullanılabilir. Kan şekerindeki değişim eğilimlerini gerçek zamanlı olarak göstererek, klinisyene ayrıntılı bilgi verir. Pediatrik hastalarda kardiyak cerrahi sonrası kullanıldığında, vücut ISISI, inotroplar ve ödemden etkilenmediği bildirilmiştir. Düşük kan glukoz seviyelerinde güvenilirliğinin düşük olması ve günde 4 kez kalibre edilmesi gerekliliği dezavantajlarıdır. Sensör 7 gün boyunca ölçüm doğruluğu etkilenmeden yerinde kalabilir. Glukoz seviyelerinin düşmekte ya da yükselmekte olduğunu göstermesi, kan alma zamanlarını belirlemekte yararlı olabilir. Hem hipoglisemi, hem de hiperglisemiye duyarlı olan prematürelerde kullanımı önerilebilir, ancak standart klinik kullanımın bir parçası olmadan önce daha kapsamlı değerlendirilmeleri gerekir (35).

Laboratuvar yöntemleri: En güvenilir yöntemdir. Glukoz oksidaz (kalorimetrik) yöntemi ya da glukoz elektrot yöntemiyle ölçüm yapılabilir (31). Tam kan glukoz değeri, plazma glukoz değerinden \%10-15 daha düşük olup, oda ISısında bekleyen kan örneğindeki glukoz seviyesi saatlik 14-18 mg/dl'ye varan düşüş gösterir (36). Arteryal örneklerdeki glukoz konsantrasyonu, venöz ve kapiller örneklere göre hafifçe yüksektir (31).

Non-invazif yöntemler: Transdermal spektrofotometrik yöntemler ya da erişkin diyabet hastalarında kullanılan ters iyontoforez yöntemi üzerinde çalışılmaktadır. Henüz yenidoğanda kullanılan non-invazif bir cihaz yoktur (35).

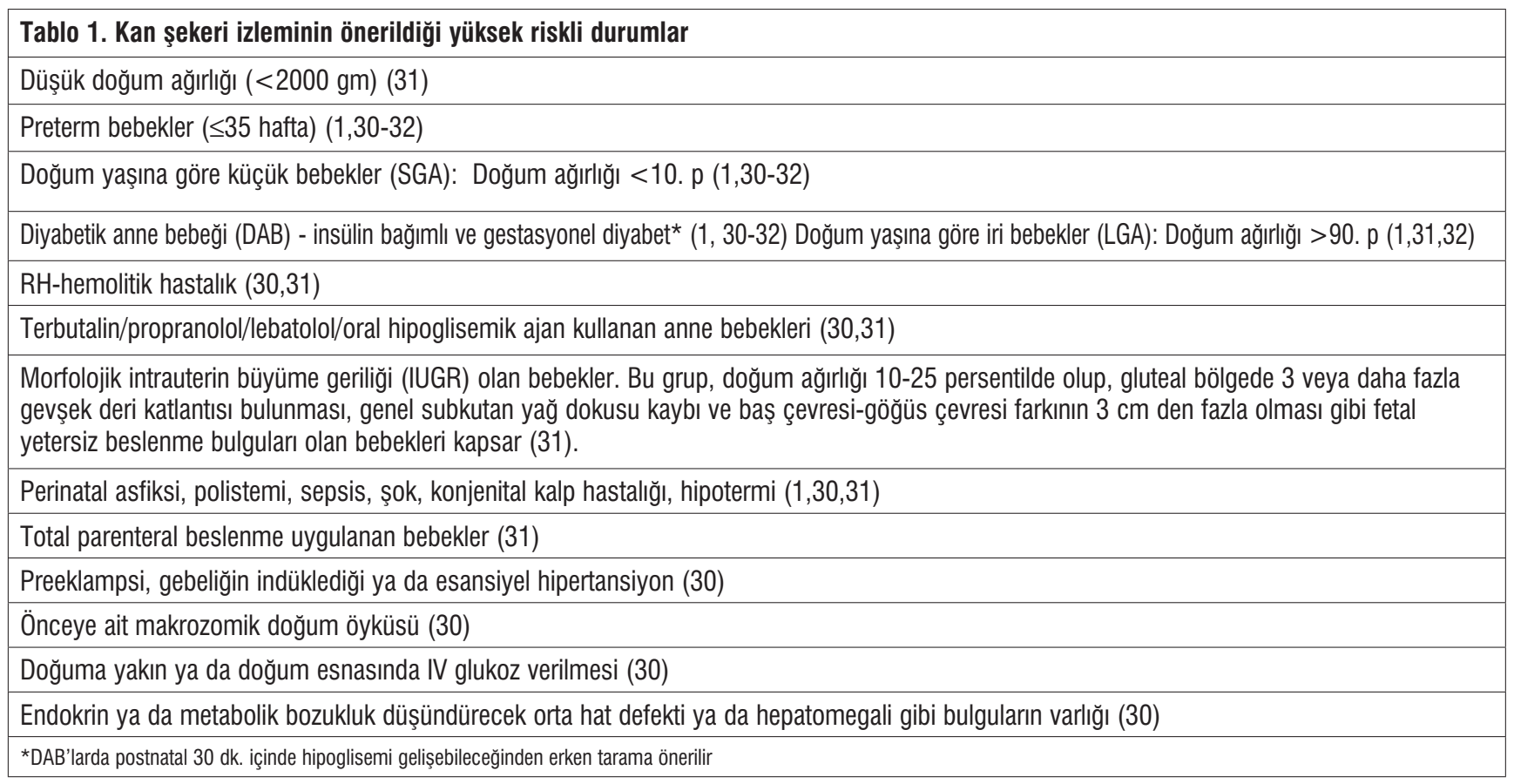




\section{Yenidoğanda Hipoglisemi Nedenleri}

Yenidoğan hipoglisemileri geçici ya da kalıcı karakterde olabilir. Geçici hipogisemiler sıklıkla açlığa adaptasyonda gelişimsel immatürite ya da substrat azlığı ile birliktedir. Normal AGA bebeklerde ilk beslenme doğumdan sonraki 6 saat içinde gerçekleşmediği takdirde kan şekerinin 30 $\mathrm{mg} / \mathrm{dl}$ altına düşme sıklı̆ı \%10 olarak bildirilmiştir (5). Bazı maternal faktörler de geçici kan şekeri düşüklüğüne yol açabilirken, metabolik ve hormonal patolojiler genellikle kalıcı hipoglisemi nedenidir. Yenidoğanda hipoglisemi nedenleri Tablo 3'de özetlenmiştir

Etyolojide yer alan bazı özellikli durumlardan aşağıda söz edilmiştir.

\section{Hiperinsülinizm}

Yenidoğan döneminde hem geçici hem de kalıcı hipoglisemilerin en sık sebebidir. Hiperinsülinizm $(\mathrm{HI})$ genetik, klinik ve morfolojik olarak heterojen bir grubu ifade eder. Lösin duyarlı hipoglisemi, adacık disregülasyon sendromu, bebeklik döneminin persistan hiperinsülinemik hipoglisemisi ve nezidioblastozis gibi isimlerle de adlandırımıştır. Ancak adacık neogenezinin erken süt çocukluğu döneminde normal bir bulgu olduğu artık bilinmektedir ve nesidioblatozis terimi kullanılmamaktadır (37-40). Sulfonilüre reseptör 1 (SUR-1; ABCC8 ile kodlanır), potasyum ATP (KATP)kanal proteini (Kir6.2; KCNJ11 ile kodlanır); glukokinaz (GK; GCK ile kodlanır); glutamat dehidrogenaz (GDH; GLUD-1 ile kodlanır); kIsa zincirli 3- hidroksiaçil-KoA dehidrogenaz (SCHAD; HADH ile kodlanır) genlerinde mutasyonlar ve SLC16A1 geninin $\beta$-hücre membranı üzerinde ektopik ekspresyonu (monokarboksilat transporter 1 (MCT1)' i kodlar) ile ilişkili bulunmuştur (41-43).

KATP kanal hiperinsülinizmi, hiperinsülinizmlerin en sık ve en ağır formudur. Diazoksit KATP kanalı üzerinden etkili olduğundan, bu durumda etkisizdir. Difüz ve fokal olarak iki formu vardır. Difüz formu otozomal resesif olarak kalıtılır ve bu hastalar, sıklıkla doğumdan hemen sonra ağır hipoglisemileri olan iri bebeklerdir $(37,38)$. Fokal hiperinsülinizm paternal izoparental izodizomi sonucu

\begin{tabular}{|l|l|}
\hline \multicolumn{2}{|l|}{ Tablo 2. Yenidoğanda hipoglisemi belirti ve bulguları } \\
\hline Anormal ağlama $(30,31)$ & Nöbetler $(30,33)$ \\
\hline Beslenme güçlüğü $(30,31)$ & Siyanoz $(30,31)$ \\
\hline Hipotermi $(30,31)$ & Solukluk $(30,31,33)$ \\
\hline Terleme $(30,31)$ & Takipne $(30,31)$ \\
\hline Tremor ve jitteriness $(30,31,33)$ & Taşikardi $(33)$ \\
\hline Hipotoni $(30)$ & Apne $(30,31,33)$ \\
\hline Irritabilite $(30)$ & Koma $(33)$ \\
\hline Letarji $(30,31)$ & Kardiyak arrest $(30,31)$ \\
\hline
\end{tabular}

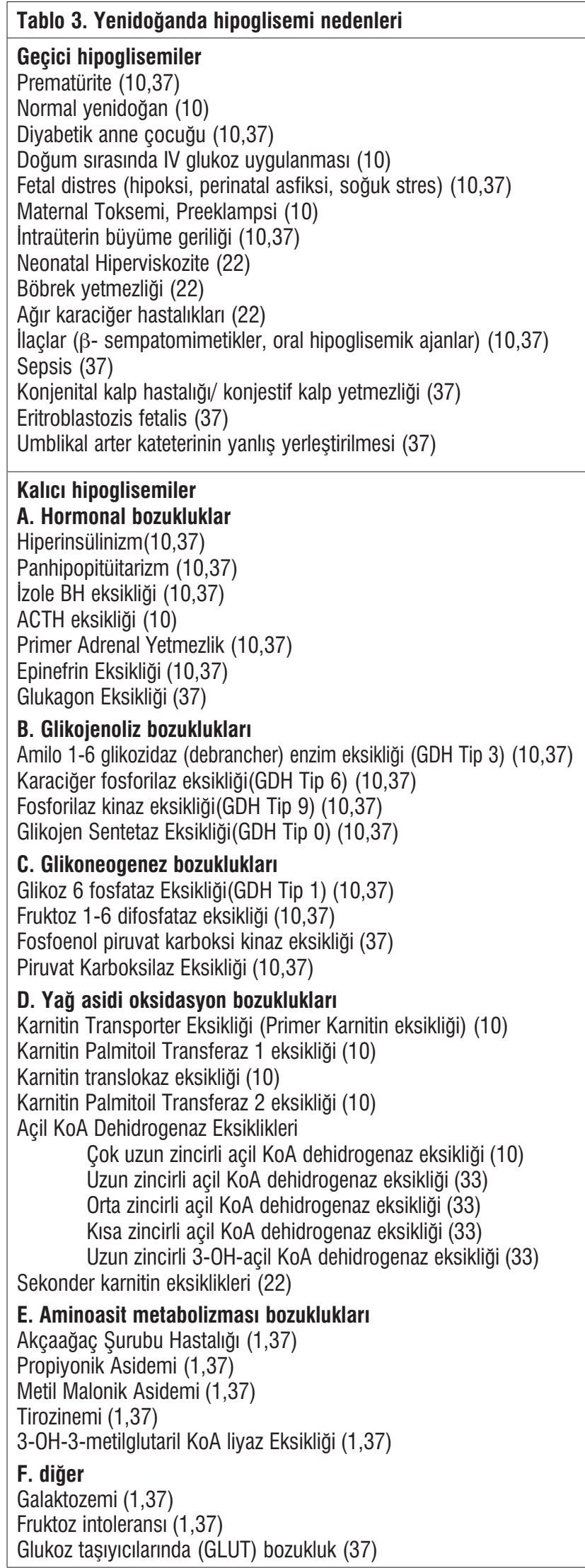


oluşur ve aynı klinik tabloya sahip ancak cerrahiye yanıt verebilen hasta grubunu oluşturur (29). Klasik tedavilere yanıt vermeyen durumlarda nifedipinin 0,5-0,8 mg/kg/gün dozunda belirgin yan etki gözlenmeden kullanılabileceği bildirilmiştir $(44,45)$.

Glutamat dehidrogenazın aktive edici mutasyonu sonucu oluşan hiperinsülinizm-hiperamonemi sendromunda artmış doğum ağırlığı sabit bir bulgu değildir ve hastaların pek azında yaşamın ilk haftasında hipoglisemi gözlenir. Muhtemelen bu genin beyinde aşııı ekspresyonuna bağlı olarak hastaların yarısında nöbet gözlenir. Hiperinsülinizmlerin ikinci sıkıkta görülen formudur. Kanıtlanmış GLUD1 mutasyonu olup serum amonyak seviyeleri normal bulunan bir hasta da bildirilmiştir $(29,38,46)$.

Glikokinaz mutasyonlarında, $\beta$-hücrelerinin glukozla uyarıma eşiği düşmüştür ve $27 \mathrm{mg} / \mathrm{dl}$ gibi düşük glukoz değerlerinde bile insülin salgılanabilir (39). Hastalığın başlangıç yaşı ve şiddeti oldukça değişkendir $(47,48)$.

Hiperinsülinizm ve hipoglisemi, hepatosit nükleer faktör 4- $\alpha$ (HNF4A) geni mutasyonu ile de birliktelik gösterebilir ve bu hastalarda yaşla birlikte sulfonilürelere yanıtlı MODY1 gelişebileceği gösterilmiştir $(49,50)$. Diyabetik anne bebekleri, doğum yaşına göre iri bebekler, perinatal stres (doğum asfiksisi, maternal toksemi, prematürite, IUGR), eritroblastozis fetalis, Beckwith-Wiedemann Sendromu, insülin uygulanması (Munchausen by Proxy ya da hiperglisemi sebebiyle), kan transfüzyonu ve umblikal arter kateterinin yanlış yerleştirilmesi de hiperinsülinizm sebepleri arasındadır $(10,29,37,38)$.

Hiperinsülinizm tanısı için kan şekeri düşükken alınan kritik örnekte bakılan plazma insülin seviyesinin $>2 \mu \mathrm{lU} /$ $\mathrm{ml}$, plazma serbest yağ asidi düzeylerinin $<1,5 \mathrm{mmol} / \mathrm{L}$, plazma $\beta$-hidroksibütirat seviyesinin $<2 \mathrm{mmol} / \mathrm{L}$ olması ve glukagona abartılı glisemik yanıt (1mg IV glukagon ile $\Delta$ glukoz > 30 mg/dl) saptanması gereklidir (10).

\section{Karșı-Düzenleyici Hormon Eksiklikleri}

Sıklıkla glukokortikoid ya da büyüme hormonu eksikliğine bağlıdır. Daha büyük çocuklarda ketotik hipoglisemi ile birlikte ortaya çıksa da, neonatal dönemde hiperinsülinizmi taklit eder şekilde hipoketotik olabilir. Orta hat defektleri, hiperpigmentasyon, kolestatik karaciğer hastalıklarına benzeyen karaciğer disfonksiyonu, erkek çocuklarda inmemiş testis ve mikropenis gibi bulguların varlığında akla getirilmelidir. Tedavisi eksik olan hormonun yerine konmasıdır $(1,10,37)$.

\section{Glikojen Depo Hastalıkları}

Farklı dokularda anormal miktarda ya da yapıda glikojen depolanmasıyla karakterize kalıtsal hastalıklardır. En çok etkilenen organlar karaciğer ve kastır. Tüm glikojen depo hastalıklarının (GDH) yaklaşık insidansı 20.000-40.000 canlı doğumda 1 olarak bildirilmiştir (51).
Glikoz-6 fosfataz eksikliği (GDH Tip 1), ilk kez 1952'de tanımlanmış olup, ilk tanımlanan kalıtsal enzim eksikliklerinden biridir (52). Hem glikojenoliz, hem glukoneogenez yolu bozuk olduğundan, glikojen depo hastalıklarının en ağır formudur. Erken dönemde sık beslenen yenidoğanda bulgu vermeyebilir, ancak herhangi bir şekilde aç kalan bebekte ağır hipoglisemi gelişir ve hepatomegali doğumdan kısa bir süre sonra fark edilir. Artmış olan laktat ve keton cisimleri, hipoglisemi semptomlarından kısmen korunmayı sağlayabilir. GDH Tip 1 b'de artan yaşla birlikte, hematolojik problemler ve inflamatuvar barsak hastalıkları gözlenebilir $(7,10,51)$.

Glikojen depo hastalıklarının bu yaş gurubundaki tedavisi, yenidoğanı sık beslemek ve eşlik edebilecek enfeksiyöz, hematolojik, metabolik sorunları gidermek şeklinde özetlenebilir. Ancak özellikle GDH Tip 1 ve Tip 2 için gündemde olan enzim replasman tedavisi ve gen tedavileri gelecekte küratif yaklaşımlar geliştirebilmek açısından umut vericidir $(53,54)$.

\section{Galaktozemi}

Klasik galaktozemiden Galaktoz-1-fosfat-üridiltransferaz eksikliği sorumludur. Daha nadir olarak galaktoz1,4-epimeraz ve galaktokinaz eksiklikleri de görülebilir. Sütle karşılaştıktan sonra birkaç gün içinde ortaya çıkan kusma, diyare ve hipoglisemi gözlenir. E.coli sepsisi ve/ veya hepatomegali ve idrarda redüktan madde pozitifliği saptanır $(33,37)$. Ileri yaşlarda katarakt, karaciğer fonksiyon bozukluğu, renal tübüler asidoz ve over yetersizliğine yol açabilir.

\section{Yağ Asidi Oksidasyon Bozuklukları}

Yağ asitleri, açlıkta önemli birer enerji kaynağıdırlar. Karaciğer hücresinde yağ asitlerinden $\beta$-oksidasyonla açil KoA'lar oluşturulur. Karaciğer, bu oluşan açil KoA'ların $\% 90$ 'ını beyni de içeren birçok dokuda alternatif eneri kaynağı olan keton cisimlerini oluşturmak için kullanır. Bu reaksiyon temel olarak mitokondride gerçekleşir, ancak yağ asitleri peroksizomlar ve stoplazmada da kısmen metabolize edilirler $(33,55)$.

Orta zincirli açil KoA dehidrogenaz eksikliği en sık görülen formudur; insidansı 1/16,400-1/46,000 arasındadır. Yaşamın 4. gününden itibaren başlayabilen ve genellikle prodromal bir hastalığı izleyen epizodik hipoketotik hipoglisemi, apne, Reye-benzeri ensefalopati ve ani bebek ölümü bildirilmiştir. Hastaların yaklașık \%4'ü ilk 72 saatte tanı almadan ölür. Metabolik asidoz, hiperamonemi, karaciğer fonksiyon testlerinde bozulma, serbest y.a. artışı, artmış açil karnitin/ serbest karnitin oranı ve sekonder karnitin eksikliği eşlik eden laboratuar bulgularıdır. Açil karnitin profilinde cis-4-dekanoat artışı tipiktir. Hastaların \%80'ininde 1p31 geninde A985G mutasyonu vardır (56-58). 
Fetüste uzun zincirli açil KoA dehidrogenaz eksikliği olduğunda, heterozigot annede HELLP sendromu (hemoliz, $\mathrm{KC}$ enzimlerinde artıs, trombositopeni), hiperemezesis gravidarum ya da yağlı karaciğer gözlenebilir (59).

\section{Laboratuvar}

Bir yenidoğanda persistan hipoglisemi varsa, sebebi belirsizse ve beklenmedik şekilde şiddetliyse nedene yönelik araştırmalar yapılmalıdır (33). Tetkiklerin hipoglisemi esnasında alınması önerilir. Hipoglisemi anında örnek almak mümkün olmazsa, hastanede uygun koşullarda açlık testi yapılarak örnek elde edilebilir. Hemen çalışılamayacak testler için idrar ve kan $-20^{\circ} \mathrm{C}$ 'de dondurularak saklanır.

\section{Tedavi}

Hipoglisemi tedavisi özellikle de hasta semptomatikse acildir ve nedene yönelik araştırmalar devam ederken başlatılmalıdır $(33,37)$.

\section{Asemptomatik Hipoglisemi}

Asemptomatik term bebeklerde $20 \mathrm{mg} / \mathrm{dl}$ düzeylerindeki kan glukoz değerlerinde bile anne sütünün erken başlatıması, sık emzirme ve kanguru bakımı (tentene temas) yöntemlerinin vücut IsıSı ve güvenli kan glukoz seviyelerini sağlamakta başarılı bulunduğu bildirilmiş ve ileri araştırma ancak hipoglisemi 48 saatten uzun sürerse önerilmiştir $(1,60)$. Retrospektif bir çalışmada, gestasyonel diyabetli anne bebeklerinde bile erken anne sütü alımı başlatıldığında hipoglisemi sıklı̆ında azalma gözlenmiştir (61). Hasta, anne sütü ya da anne sütü yokluğunda formula ile beslendikten 1 saat sonra kan şekeri ölçülür, $50 \mathrm{mg} / \mathrm{dl}$ ve üstündeyse 2 saatlik aralarla beslenme sağlanarak, 48 saat boyunca 6 saatte bir kan şekeri izlemi yapııır. Tekrar hipoglisemi gelişmezse izlem

\begin{tabular}{|l|l|}
\hline \multicolumn{2}{|l|}{ Rutin Tetkikler (1,22,33,37) } \\
\hline Kanda & $\begin{array}{l}\text { Glukoz, serbest yağ asitleri, keton, laktat, ürik asit, } \\
\text { amonyak, ALT/AST, kan gazı, üre, Na, K, insülin, } \\
\text { kortizol, BH }\end{array}$ \\
\hline Idrarda & Keton, redüktan madde \\
\hline
\end{tabular}

\begin{tabular}{|c|c|}
\hline \multicolumn{2}{|c|}{ İleri Tetkik } \\
\hline Kanda & $\begin{array}{l}\text { Aminoasit, piruvat, gliserol, Total/serbest karnitin, } \\
\text { Açil karnitin, c-peptid, T4,TSH, ACTH, IGFBP-1, } \\
\text { glukagon, epinefrin, norepinefrin, enzim tayini, } \\
\text { mutasyonu için DNA }\end{array}$ \\
\hline Idrarda & Organik asit, açil karnitin \\
\hline
\end{tabular}

sonlandırıır. Hastanın kan glukoz seviyesi beslenmenin ardından $<40 \mathrm{mg} / \mathrm{dl}$ ise intravenöz glukoz başlanır ve hastanın bundan sonraki takibi semptomatik hipoglisemi gibi yapılır. Asemptomatik, ancak kan glukoz seviyesi 20 $\mathrm{mg} / \mathrm{dl}$ altında bulunan bebeklerde ise yaklaşı $6 \mathrm{mg} / \mathrm{kg} / \mathrm{dk}$ hızda glukoz infüzyonu bașlanır (31).

\section{Semptomatik hipoglisemi}

Uygun kan örneği alındıktan hemen sonra 2-4 cc/kg $\% 10$ deksroz (nöbet varsa $4 \mathrm{cc} / \mathrm{kg}$ tercih edilir), intravenöz olarak 4-6 dk'da verilir ve ardından 6-8 mg/kg/dk glukoz infüzyonu başlatıır. Kan şekeri 5-10 ve 30-60 dk sonra kontrol edilir. Eğer artıș yoksa bolus tekrarlanır ve perfüzyon hızı 12 mg/kg/dk'ya ulașıncaya dek 1-2 mg/kg/dk arttırıır. Yirmidört saatlik intravenöz tedavinin ardından, kan glukoz düzeyi takibinde üst üste $2 \mathrm{kez} 50 \mathrm{mg} / \mathrm{dl}$ ve üstü değer görülürse glukoz infüzyon hızı her 6 saate bir $2 \mathrm{mg} / \mathrm{kg} /$ dk azaltıırken, oral beslenme arttırılır. Kan glukoz seviyeleri sürekli olarak $>50 \mathrm{mg} / \mathrm{dl}$, oral beslenmesi yeterli olan hastada glukoz infüzyon hızı $4 \mathrm{mg} / \mathrm{kg} / \mathrm{dk}$ 'ya düşüldükten sonra intravenöz SIVI sonlandırıır $(1,22,31,37)$.

\section{Tekrarlayan/dirençli hipoglisemi}

Eğer 10,5-12 mg/kg/dk'yı aşan glukoz infüzyon hızı ile 5-7 günde kan glukoz seviyeleri istenilen düzeye gelmiyorsa ileri tedavi düşünülmelidir $(1,31)$. Periferik venden verilebilecek maksimum glukoz konsantrasyonu için \%10 ve \%20 arasında değerlerden söz edilmekle beraber, \%12,5'u aşan glukoz konsantrasyonlu mayi kullanılacaksa santral ven tercih etmek bugün için güvenli bir yol gibi görünmektedir $(1,29,31,33,61)$. Tekrarlayan ya da dirençli hipoglisemilerde şu ilaçlar kullanılabilir:

(1)- Glukagon $100 \mu \mathrm{g} / \mathrm{kg}$ subkutan ya da intramüsküler olarak uygulanabilir (maksimum $300 \mu \mathrm{g}, 3 \mathrm{doz}$ ). Hepatik glikojen depolarını serbestleştirir, glukoneogenezi artııır ve ketogeneze öncülük eder. SGA bebeklerde bu etkiler her zaman görülmez ve kullanımı pek önerilmez. Kusma, diyare, hipokalemi gibi yan etkileri vardır ve yüksek dozlarda insülin salınımını uyarabilir.

(2)- Hidrokortizon 5 mg/kg/gün IV/ PO, 2 dozda 2448 saat süreyle önerilir. Adrenal yetmezlik dışında etkisi sınırlıdır.

(3)- Diazoksit 10-25 mg/kg/gün 3-4 dozda verilebilir. Beta hücrelerindeki KATP kanallarını açık tutarak, insülin sekresyonunu azaltır. Hirsutizm, ödem, hiperürisemi, elektrolit bozuklukları, kemik yaşında ilerleme, Ig G eksikliği gibi birçok bildirilmiş yan etkisi vardır.

(4)- Oktreotid (sentetik somatostatin), KATP kanalının genetik olmayan bozukluklarında ve adacık hücre adenomlarında etkilidir. Subkutan olarak, 2-10 $\mu \mathrm{g} / \mathrm{kg} / \mathrm{gün}$ dozunda 2-4 kez/gün kullanılabilir. Sık görülmeyen ancak potansiyel yan etkileri büyüme geriliği, kusma, diyare ve hepatik disfonksiyondur. 
Eksikliklerinin saptanması durumunda büyüme hormonu ve epinefrin kullanılabilir. Galaktozemi gibi durumlarda ilgili maddeden sakınma, glikojen depo hastalıklarında sık beslenme önerilir. Medikal tedavi ile kontrol altına alınamayan hiperinsülinizm olgularında pankreatektomi uygulanmaktadır $(1,5,10,26,31)$.

\section{Kaynaklar}

1. Williams AF. Hypoglycaemia of the newborn: a review. Bull World Health Organ 1997;75:261-90.

2. Wolfsdorf $\mathrm{JI}$, Weinstein DA. Hypoglycemia in children. In: Lifshitz $F($ ed). Pediatric Endocrinology. 5th ed. New York: Informa; 2007. p. 291-319.

3. Lteif AN, Schwenk WF. Hypoglycemic disorders. Endocrinol Metab N Am 1999;28:619-46.

4. Cornblath M, Ichord R. Hypoglicemia in the neonate. Semin Perinatol 2000;24:136-49.

5. Gutberlet RL, Cornblath M. Neonatal hypoglycemia revisited. Pediatrics 1975;58:10-7.

6. Hartmann AF, Jaudon JC. Hypoglycaemia. J Pediatr 1937;11:1.

7. Cornblath M, Odell GB, Levin EY. Symptomatic neonatal hypoglycaemia associated with toxaemia of pregnancy. J Pediatr 1959;55:545-62.

8. Cowett RM, Farrag HM. Selected principles of perinatalneonatal glucose metabolism. Semin Neonatol 2003;9:37-47.

9. Kalhan SC, D'Angelo LJ, Savin SM, Adam PA. Glucose production in pregnant women at term gestation. Sources of glucose for human fetus. J Clin Invest 1979;63:388-94.

10. De Leon DD, Stanely CA, Sperling MA. Hypoglycemia in Neonates and Infants. In: Sperling MA (ed) .Pediatric Endocrinology, 3rd ed. Philedelphia: Saunders Elsevier Co; 2008. p. 166-93.

11. Srinivasan G, Pildes RS, Cattamanchi G, Voora S, Lilien LD. Plasma glucose values in normal neonates: a new look. J Pediatr 1986;109:114-7.

12. Raju TN, Higgins RD, Stark AR, Leveno KJ. Optimizing care and outcome for late-preterm (near-term) infants: a summary of the workshop sponsored by the National Institute of Child Health and Human Development. Pediatrics 2006;118:1207-14.

13. Duvanel CB, Fawer CL, Cotting J, Hohlfeld P, Matthieu JM. Long-term effects of neonatal hypoglycemia on brain growth and psychomotor development in small-for-gestational-age preterm infants. J Pediatr 1999;134:492-8.

14. Dalgiç N, Ergenekon E, Soysal S, Koç E, Atalay $Y$, Gücüyener K. Transient neonatal hypoglycemia--long-term effects on neurodevelopmental outcome. J Pediatr Endocrinol Metab 2002;15:319-24.

15. Auer RN. Hypoglycemic brain damage. Metab Brain Dis 2004;19:169-75.

16. Vannucci RC, Vannucci SJ. Hypoglycemic brain injury. Semin Neonatol 2001;6:147-55.

17. Brand PL, Molenaar NL, Kaaijk C, Wierenga WS. Neurodevelopmental outcome of hypoglycaemia in healthy, large for gestational age, term newborns. Arch Dis Child 2005;90:78-81.
18. Moore H, Craft TK, Grimaldi LM, Babic B, Brunelli SA, Vannucci SJ. Moderate recurrent hypoglycemia during early development leads to persistent changes in affective behavior in the rat. Brain Behav Immun 2010;24:839-49.

19. Koh TH, Eyre JA, Aynsley-Green A. Neonatal hypoglycaemia: the controversy regarding definition. Arch Dis Child 1988;63:1386-8.

20. Cornblath M, Hawdon JM, Williams AF, Aynsley-Green A, Ward-Platt MP, Schwartz $R$ et al. Controversies regarding definition of neonatal hypoglycemia: suggested operational thresholds. Pediatrics 2000;105:1141-5.

21. Sperling MA. Hypoglycemia. In: Behrman RE, Kliegman RM, Jenson HB (eds). Nelson Textbook of Pediatrics, 17th Ed. Philedelphia: Saunders; 2004. p. 505-18.

22. Nicolini U, Hubinont C, Santolaya J, Fisk NM, Coe AM, Rodeck $\mathrm{CH}$. Maternal-fetal glucose gradient in normal pregnancies and in pregnancies complicated by alloimmunization and fetal growth retardation. Am J Obstet Gynecol 1989;161:924-7.

23. Economides DL, Nicolaides KH. Blood glucose and oxygen tension levels in small-for-gestational-age fetuses. Am J Obstet Gynecol 1989;160:385-9.

24. Lucas A, Morley R, Cole TJ. Adverse neurodevelopmental outcome of moderate neonatal hypoglycaemia. BMJ 1988;297:1304-8.

25. Rozance PJ, Hay WW Jr. Describing hypoglycemia--definition or operational threshold? Early Hum Dev 2010;86:275-80.

26. Cornblath M, Schwartz R. Outcome of neonatal hypoglycemia Complete data are needed. BMJ 1999;318:194-5.

27. Hay WW Jr, Raju TN, Higgins RD, Kalhan SC, Devaskar SU. Knowledge gaps and research needs for understanding and treating neonatal hypoglycemia: workshop report from Eunice Kennedy Shriver National Institute of Child Health and Human Development. J Pediatr 2009;155:612-7.

28. Straussman S, Levitsky LL. Neonatal hypoglycemia. Curr Opin Endocrinol Diabetes Obes 2010;17:20-4.

29. Rozance PJ, Hay WW. Hypoglycemia in newborn infants: Features associated with adverse outcomes. Biol Neonate 2006;90:74-86.

30. Ashish J, Aggarwal R, Jeeva Sankar M, Agarwal R, Deorari AK, Paul VK. Hypoglycemia in the newborn. Indian J Pediatr 2010; $77: 1137-42$.

31. Croke J, Sullivan M, Ryan-Drover A, Randell E, Andrews W, Aziz $\mathrm{K}$. Two hour blood glucose levels in at-risk babies: An audit of Canadian guidelines. Paediatr Child Health 2009;14:238-44.

32. Marles SL, Casiro OG. Persistent neonatal hypoglycemia: Diagnosis and management. Paediatr Child Health 1998;3:16-9.

33. Jain R, Myers TF, Kahn SE, Zeller WP. How accurate is glucose analysis in the presence of multiple interfering substances in the neonate? (glucose analysis and interfering substances). J Clin Lab Anal 1996;10:13-6.

34. Beardsall K. Measurement of glucose levels in the newborn. Early Hum Dev 2010;86:263-7.

35. Cowett RM, D'Amico LB. Capillary (heelstick) versus venous blood sampling for the determination of glucose concentration in the neonate. Biol Neonate 1992;62:32-6.

36. Darendeliler F. Hipoglisemi. In: Günöz H, Öcal G, Yordam N, Kurtoglu $S$ eds. Pediatrik Endokrinoloji. Istanbul: Pediatrik Endokrinoloji ve Oksoloji Derneği Yayınları Dernek Kitabı; 2003. s. $457-85$. 
37. Palladino AA, Bennett MJ, Stanley CA. Hyperinsulinism in infancy and childhood: when an insulin level is not always enough. Ann Biol Clin (Paris) 2009;67:245-54.

38. DeLeon DD, Stanley CA. Mechanisms of disease: advances in diagnosis and treatment of hyperinsulinism in neonates. Nat Clin Pract Endocrinol Metab 2007;3:57-68.

39. Rahier J, Guiot Y, Sempoux C. Persistent hyperinsulinaemic hypoglycaemia of infancy: a heterogeneous syndrome unrelated to nesidioblastosis. Arch Dis Child Fetal Neonatal Ed 2000;82:F108-12.

40. Clayton PT, Eaton S, Aynsley-Green A, Edginton M, Hussain $\mathrm{K}$, Krywawych $\mathrm{S}$ et al. Hyperinsulinism in short-chain L-3hydroxyacyl-CoA dehydrogenase deficiency reveals the importance of oxidation in insulin secretion. J Clin Invest 2001;108:457-65.

41. Stanley CA, Lieu YK, Hsu BY, Burlina AB, Greenberg CR, Hopwood NJ et al. Hyperinsulinism and hyperammonemia in infants with regulatory mutations of the glutamate dehydrogenase gene. N Engl J Med 1998;338:1352-7.

42. Otonkoski T, Jiao H, Kaminen-Ahola N, Tapia-Paez I, Ullah MS, Parton LE et al. Physical exercise- induced hypoglycemia caused by failed silencing of monocarboxylate transporter 1 in pancreatic _ cells. Am J Hum Genet 2007;81:467-74.

43. Bas F, Darendeliler F, Demirkol D, Bundak R, Saka N, Günöz H. Successful therapy with calcium channel blocker (nifedipine) in persistent neonatal hyperinsulinemic hypoglycaemia of infancy. J Pediatr Endocrinol Metab 1999;12:873-8.

44. Suprasongsin C, Suthutvoravut U, Mahachoklertwattana P, Preeyasombat C. Combined raw cornstarch and nifedipine as an additional treatment in persistent hyperinsulinemic hypoglycaemia of infancy. J Med Assoc Thai 1999;82:39-42.

45. Kapoor RR, Flanagan SE, Fulton P, Chakrapani A, Chadefaux B, Ben-Omran T et al. Hyperinsulinism-hyperammonaemia syndrome: novel mutations in the GLUD1 gene and genotypephenotype correlations. Eur J Endocrinol 2009;161:731-5.

46. Gloyn AL, Noordam K, Willemsen MA, Ellard S, Lam WW, Campbell IW et al. Insights into the biochemical and genetic basis of glucokinase activation from naturally occurring hypoglycemia mutations. Diabetes 2003;52:2433-40.

47. Cuesta-Munoz AL, Huopio H, Otonkoski T, Gomez-Zumaquero JM, Nanto-Salonen K, Rahier $J$ et al. Severe persistent hyperinsulinemic hypoglycemia due to a de novo glucokinase mutation. Diabetes 2004;53:2164-8.
48. Kapoor RR, Locke J, Colclough K, Wales J, Conn JJ, Hattersley AT et al. Persistent hyperinsulinemic hypoglycemia and maturity-onset diabetes of the young due to heterozygous HNF4A mutations. Diabetes 2008;57:1659-63.

49. Pearson ER, Boj SF, Steele AM, Barrett T, Stals K, Shield JP et al. Macrosomia and hyperinsulinaemic hypoglycaemia in patients with heterozygous mutations in the HNF4A gene. PLoS Med 2007;4:e118.

50. Mayatepek E, Hoffmann B, Meissner T. Inborn errors of carbohydrate metabolism. Best Pract Res Clin Gastroenterol 2010;24:607-18.

51. Cori GT, Cori CF. Glucose-6-phosphatase of the liver in glycogen storage disease. J Biol Chem 1952;199:661-7.

52. Koeberl DD, Kishnani PS, Chen YT. Glycogen storage disease types I and II: treatment updates. J Inherit Metab Dis 2007;30:159-64.

53. Yiu WH, Pan CJ, Allamarvdasht M, Kim SY, Chou JY. Glucose6-phosphate transporter gene therapy corrects metabolic and myeloid abnormalities in glycogen storage disease type lb mice. Gene Ther 2007;14:219-26.

54. Hale DE, Bennett MJ. Fatty acid oxidation disorders: a new class of metabolic diseases. J Pediatr 1992;121:1-11.

55. Touma EH, Charpentier C. Medium chain acyl-CoA dehydrogenase deficiency. Arch Dis Child 1992;67:142-5.

56. Catzeflis C, Bachmann C, Hale DE, Coates PM, Wiesmann U, Colombo JP et al. Early diagnosis and treatment of neonatal medium chain acyl-CoA dehydrogenasedeficiency: report of two siblings. Eur J Pediatr 1990;149:577-81.

57. Wilcken B. Fatty acid oxidation disorders: outcome and longterm prognosis. J Inherit Metab Dis 2010;33:501-6.

58. Pollitt RJ. Disorders of mitochondrial long chain fatty acid oxidation. J Inher Metab Dis 1995;18:473-90.

59. Hewitt V, Watts R, Robertson J, Haddow, G. Nursing and midwifery management of hypoglycaemia in healthy term neonates. Int J Evid Based Healthc 2005;3:169-205.

60. Chertok IR, Raz I, Shoham I, Haddad H, Wiznitzer A. Effects of early breastfeeding on neonatal glucose levels of term infants born to women with gestational diabetes. J Hum Nutr Diet 2009;22:166-9.

61. Vanhatalo T, Tammela 0 . Glucose infusions into peripheral veins in the management of neonatal hypoglycemia--20\% instead of 15\%? Acta Paediatr 2010;99:350-3. 